\title{
Article \\ Early Biological Response of an Ultra-Hydrophilic Implant Surface Activated by Salts and Dry Technology: An In-Vitro Study
}

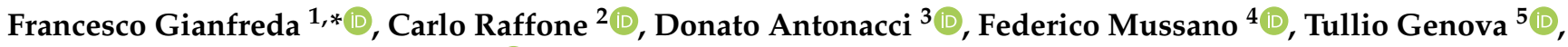 \\ Giorgia Chinigò $^{5}$, Luigi Canullo ${ }^{2}(\mathbb{D})$ and Patrizio Bollero ${ }^{6}$
}

\section{check for} updates

Citation: Gianfreda, F.; Raffone, C.; Antonacci, D.; Mussano, F.; Genova, T. Chinigò, G.; Canullo, L.; Bollero, P. Early Biological Response of an Ultra-Hydrophilic Implant Surface Activated by Salts and Dry Technology: An In-Vitro Study. Appl. Sci. 2021, 11, 6120. https://doi.org/ 10.3390/app11136120

Academic Editors: Maria Menini, Francesco Pera and Paolo Pesce

Received: 21 April 2021

Accepted: 21 June 2021

Published: 30 June 2021

Publisher's Note: MDPI stays neutral with regard to jurisdictional claims in published maps and institutional affiliations.

Copyright: (c) 2021 by the authors. Licensee MDPI, Basel, Switzerland. This article is an open access article distributed under the terms and conditions of the Creative Commons Attribution (CC BY) license (https:/ / creativecommons.org/licenses/by/ $4.0 /)$.
1 Department of Industrial Engineering, University of Rome “Tor Vergata”, 00133 Rome, Italy

2 Indipendent Researcher, 00198 Rome, Italy; raffonecarlo@hotmail.it (C.R.); luigicanullo@yahoo.com (L.C.)

Indipendent Researcher, 70121 Bari, Italy; donat.antonacci@gmail.com

4 Department of Surgical Sciences, University of Torino, Via Nizza 230, 10126 Torino, Italy; federico.mussano@unito.it

5 Department of Life Sciences and Systems Biology, University of Torino, Via Accademia Albertina 13, 10123 Torino, Italy; tullio.genova@unito.it (T.G.); giorgia.chinigo@unito.it (G.C.)

6 Department of System Medicine, University of Rome "Tor Vergata", 00133 Rome, Italy; patrizio.bollero@ptvonline.it

* Correspondence: francesco.gianfreda@ptvonline.it

Abstract: The use of dental implants has grown over the years and has led to higher success rates. To further enhance surgical outcomes, many research groups and companies have shifted their focus to surfaces roughness, wettability and chemistry. In a recent study a new dry salt bioactivate surface has been described from a chemical and physical point of view. The aim of this study is to evaluate the osteogenic response of pre-osteoblast cell lines to dry bioactivated surface. MC3T3-E1 osteogenic cell lines were cultured on SM (sandblasted and dual acid-etched surface) and HNS (SM surface with dry salts bioactive technology). Cell adhesion assay, proliferation assay and cell morphology were performed. Osteogenic activity was performed using Alizarin Red S and alkaline phosphatase. The results showed that SM surface determines a slighter but significant increase in cell adhesion and proliferation in a shorter time compared to HNS. On the contrary, HNS surface has long and intertwining filopodia that could be a response to surface HNS-topography that results in a higher stage of differentiation. The nature of the HNS surface is more prone to determine massive deposition of calcium minerals. This study is the first investigating the role of this interesting dry-salts bioactive surface during the first phase of healing and its potential biochemical advantage could be validated by future animal studies with the aim of evaluate the rate of bone implant contact in the early stages of healing.

Keywords: wettability; bioactivate implant surfaces; surface chemistry; ultra-hydrophilic implants; implants nano-surfaces; salt exsiccation layer; MC3T3-E1 osteogenic cell line

\section{Introduction}

The introduction of the osseointegration concept by Brånemark et al. [1], led the research toward the "process whereby clinically asymptomatic rigid fixation of alloplastic materials is achieved and maintained in bone during functional loading". Attention has then been focused on how to enhance the connection through material preparation and surface modification to achieve osseointegration: Topographic modifications through blasting with ceramic particles/acid etching and chemical modifications through titanium plasma spraying, electrochemical anodization, and calcium phosphate coatings have been proposed [2]. Among these surface treatments, combined etching and sandblasting have shown the best results in bone apposition and removal torque [3]. Frequently, the treatments have the purpose of increasing implant to bone surface ratio, additionally, rough surfaces 
have been demonstrated to activate osteoblast differentiation [4]. In particular, sandblasted, large grit, acid-etched implant surface (SLA) treatment reformed the same topography surface shaped by osteoclasts and the osteoblast response observed on this surface is comparable to the response on surface conditioned by osteoclast [5].

Bioactive materials are now studied, bioceramics, ions, biomolecules, to determine whether osseointegration would be achieved, how efficiently, and with what effect [6].

Engraving the surface is not enough to increase biological contact: The benefits derived from micro-porosity and roughness can be enhanced by paying attention to wettability [7]. This property steered both the adsorption of proteins and the contact between blood cells and implant by activating a different healing pattern [8]. It was noticed that hydrophilic surface promotes the differentiation of MSC in osteoblasts and stimulates the secretion of large quantities of anti-inflammatory cytokines [9]. Accordingly, achieving complete hydrophilicity is the goal to increase the success of implant therapy. Several methods have been proposed to increase wettability and obtain hydrophilicity that is featured mainly at $0^{\circ}-5^{\circ}$ contact angle (CA). $\mathrm{N}_{2}$ rinsing had a surprising effect on the implant surface: First, thanks to the extreme purity of the surface, the dynamic contact angle (DCA) was modified from $138^{\circ}$ to $0^{\circ}$ [10], turning hydrophobic surface into completely hydrophilic one, second the possibility of bonds with blood proteins is greatly increased, making the healing favorable [11]. UV light activation [12] or nonthermal atmosphericpressure plasma using different gases [13] had interesting outcomes both on hydrophilicity and decontamination. Hydrophilicity is mainly influenced by roughness and chemical inhomogeneities of surfaces [14] and high interfacial energy [15]. The roughness influences wettability because when exposed to the air, the smallest micropores on the implant surface trap air leading to different conditions lowering the wettability. Therefore, in order to maximize wettability, roughness indentation must be hierarchically structured [16]. Dental implant surface energy is initially extremely high because titanium oxide is produced when titanium is in contact with atmospheric oxygen [17]. Nevertheless, the adsorption of atmospheric hydrocarbons, caused by the high surface energy, lowered the interfacial energy in time-dependent manner and consequently the wettability, turning the surface from hydrophilic into a hydrophobic one [18]. Preventing loss of surface energy in order to preserve wettability has been a crucial aspect and an important research topic in recent years. Bayer and Meyer [19], in 1988, underlined the advantages of storage in water titanium dental implant to maintain energy surface. This evidence led to the SLActive (Sandblasted, Large grit, Acid-etched, Activated surface) technology, with the immersion of an SLA surface in a saline solution [20]. In addition, other methods were reported in order to prevent hydrocarbons deposition, such as storage in dry methanol [21] or removing hydrocarbons with chair-side devices like UV light or glow discharge [22,23]. Finally, different types of coating have been studied, such as Hyaluronan coated dental implant [24] or exsiccation of layer of potassium phosphate salt ions [25]. The dry state storage with salts showed very encouraging results in terms of wettability preservation, but the biological response with this kind of coating is still unknown. The aim of the present study is to describe the response of pre-osteoblastic cells in vitro in terms of cell adhesion, proliferation, morphology, and osteodifferentiation to a new dry bioactivated salt coated surface (HNS, Hydrophilic/Nano Scale SLA surface with dry bioactive technology) and a commercial Sub-Micron Surface Roughtness (RM).

\section{Materials and Methods}

\subsection{Ti Disc Preparation}

Five mm diameter and $1 \mathrm{~mm}$ thick discs were fabricated from Ti Grade 23 and subjected to one of the following modifications:

1. SM: Commercial Sub-Micron Roughness Surface obtained by sandblasting and acid-etching.

2. HNS: Hydrophilic/Nano Scale sandblasted and acid-etched surface with dry bioactive technology. 
A recent study [26] described SM to have a hydrophobic behavior with an estimated Contact Angle (CA) of $76.5^{\circ}$, while HNS reported a CA of $0^{\circ}$ and thus an ultrahydrophilic surface.

\subsection{Sample Size}

A power analysis was estimated on the pilot samples [27] using the mean contamination values of $117.5000 \pm 0.0054$ spots/field (control) vs. 11,348.5 \pm 0.0007 spot/field (test) $(p=0.0001)$ was projected by setting effect size $\mathrm{dz}=1.438$, error probability $\mathrm{a}=0.05$, and power $=0.95$ (1-b error probability), resulting in 6 samples from each sub-group ( $\mathrm{G}^{*}$ Power 3.1.7 for Mac OS X Yosemite, version 10.10.3).

\subsection{Cell Culture}

To characterize the biological response in vitro, a pre-osteoblastic murine cell line MC3T3E1 (ECACC) was used [28]. Cells were maintained in Alpha MEM culture medium supplemented with $10 \%$ fetal bovine serum (Gibco Life Technologies, Milan, Italy), $100 \mathrm{U} / \mathrm{mL}$ penicillin, $100 \mu \mathrm{g} / \mathrm{mL}$ streptomycin (Gibco Life Technologies, Milan, Italy). Cells were kept under a humidified atmosphere of $5 \% \mathrm{CO}_{2}$ in air, at $37^{\circ} \mathrm{C}$.

\subsection{Cell Adhesion Assay}

Cell adhesion was evaluated on titanium disks placed in a 24-well plate as support. Cells were detached using trypsin for $3 \mathrm{~min}$, carefully counted, and seeded $2 \times 103$ at cells/disk in $80 \mu \mathrm{L}$ of growth medium on the disks with different roughness. The 24-well plates were kept at $37^{\circ} \mathrm{C}, 0.5 \% \mathrm{CO}_{2}$ for $12 \mathrm{~min}$. Titanium disks were then washed twice with PBS and then fixed in $4 \%$ paraformaldehyde for $15 \mathrm{~min}$ at room temperature. Cells were stained with $1 \mu \mathrm{M}$ DAPI for $15 \mathrm{~min}$ at $37^{\circ} \mathrm{C}$ to visualize cell nucleus. Cells were counted using a Nikon Eclipse T-E microscope with $4 \mathrm{X}$ objective.

\subsection{Proliferation Assay}

In order to evaluate cell proliferation, CellTiter-Glo ${ }^{\circledR}$ Luminescent Cell Viability Assay (Promega Corporation, Madison, WI, USA) was used. This is a method of determining the number of viable cells in culture based on quantitation of the ATP present. Briefly, 3000 cells/disk were seeded, and the proliferation was assessed at 24, 48, and $120 \mathrm{~h}$ measuring the luminescence through a microplate reader (Filtermax F5; Molecular Devices LLC, San Jose, CA, USA).

\subsection{Cell Morphology}

Cells were seeded on titanium disks at a concentration of 1000 cells/disk in a 24-well plate and then kept in growth condition. After 1, 6, and $24 \mathrm{~h}$, the titanium specimens were washed in PBS and then the cells were fixed with $4 \%$ paraformaldehyde (PFA) in PBS for $15 \mathrm{~min}$. After washing with PBS, cells were permeabilized with 0.5\% Triton X-100 (SigmaAldrich) in PBS and then saturated with 1\%BSA in PBS for 40 min. In order to highlight the focal adhesion, samples of $24 \mathrm{~h}$ time point were stained with Anti-Paxillin Antibody, clone $5 \mathrm{H} 11$ (Merck Millipore) $\mathrm{O} / \mathrm{N}$ at $4{ }^{\circ} \mathrm{C}$. Then, cells were stained with Rodhamine-Phalloidin or AlexaFluor 488-Phalloidin (Life Technologies) and $1 \mathrm{uM}$ Dapi (Life Technologies) to respectively detect the cytoskeleton and the nuclei. Image acquisition was made recurring to a Nikon Eclipse Ti-E microscope with a 10X, 20X, and 60X objective (Plan Fluor Nikon). Image analysis was performed by means of ImageJ software. Then, cell area of MC3T3E1seeded on HNS and SM samples was measured.

\subsection{Osteogenic Activity}

In order to evaluate the osteogenic activity of MC3T3-E1 seeded on HNS and SM samples, the cells were cultured for 21 days in Osteogenic Medium (Alpha MEM culture medium supplemented with $10 \%$ fetal bovine serum and $50 \mu \mathrm{g} / \mathrm{mL}$ ascorbic acid, $10 \mathrm{mM}$ $\beta$-glicerophosphate, $10 \mathrm{nM}$ dexamethasone), which was changed every 3 days. 
After 21 days, Alizarin Red S staining was performed on titanium samples. In order to quantify this staining, the samples were treated with a $10 \%$ acetic acid solution, then, the absorbance at $405 \mathrm{~nm}$ of this solution was measured through a microplate reader (Filtermax F5; Molecular Devices).

Twenty-one days after osteogenic induction, the alkaline phosphatase (ALP) activity was evaluated on culture medium and on cell lysates by using a specific kit Alkaline Phosphatase Assay Kit ab83369 (Abcam), measuring the absorbance at $405 \mathrm{~nm}$ through a microplate reader (Filtermax F5; Molecular Devices).

\subsection{Statistical Analysis}

Due to the nonparametric nature of the data collected, differences between groups were analyzed using the Mann-Whitney-Wilcoxon test, by means of GraphPad Prism 7 software (GraphPad Software, Inc., La Jolla, CA, USA). All of the statistical comparisons were conducted with a 0.05 level of significance.

\section{Results}

\subsection{Cell Adhesion Assay}

To characterize the biological response in vitro, the widely used pre-osteoblastic murine cell line MC3T3-E1 was used. In particular, in order to evaluate the early biological response, the ability of the cells to adhere to the titanium discs was studied. As shown in Figure 1, SM surfaces are able to determine a significant increase in the adhesion level of MC3T3 12 min after seeding.

\section{Adhesion assay}

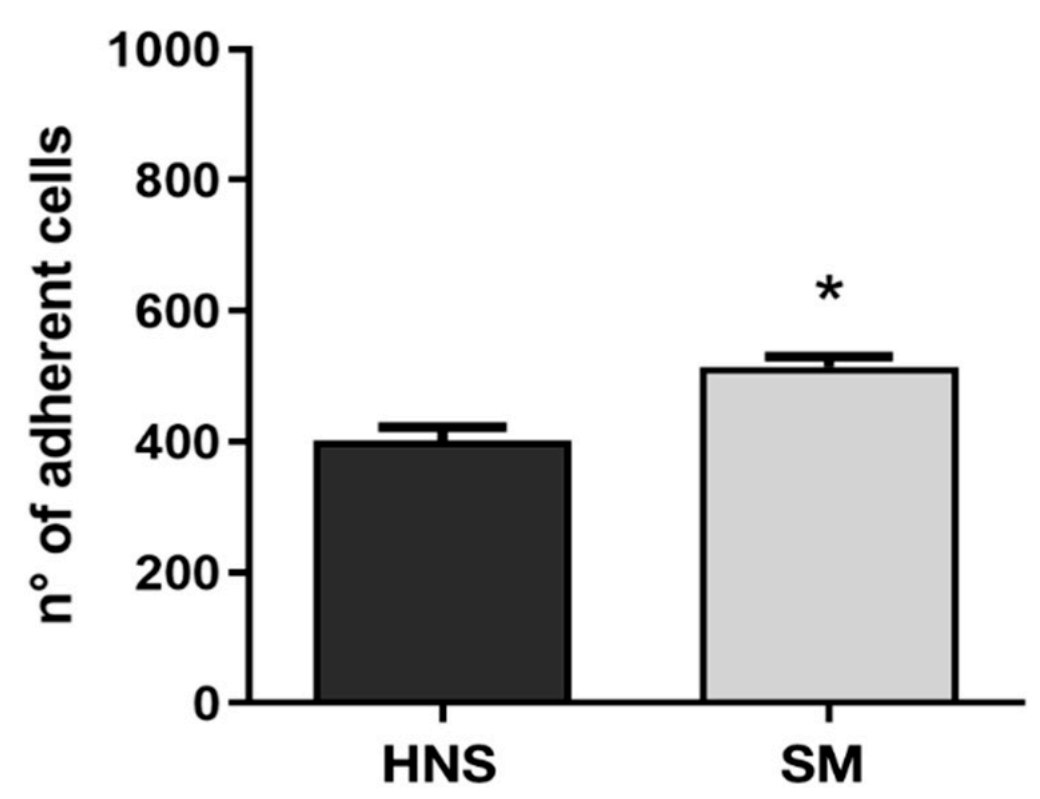

Figure 1. Cell adhesion was evaluated on all samples at $12 \mathrm{~min}$. The level of cell adhesion was measured by counting the number of adherent cells for each sample. Values represent mean \pm SEM. The symbol $(*)$ indicates the statistical significance vs. HNS surface considering a $p$-value $<0.05$.

\subsection{Cell Morphology}

To qualitatively evaluate the early cell morphology, fluorescence microscopy experiments were conducted by marking the cytoskeleton and nuclei. As can be appreciated from Figure 2, no particular alterations or differences in cell morphology are observed between MC3T3s plated on HNS and SM surfaces at T1. On the other hand, a slight difference is observed in the level of spreading, which is greater at T2 than at T1, with cells seeded on 
HNS surfaces appearing very slightly more elongated and less round than those plated on SM surfaces.

T1
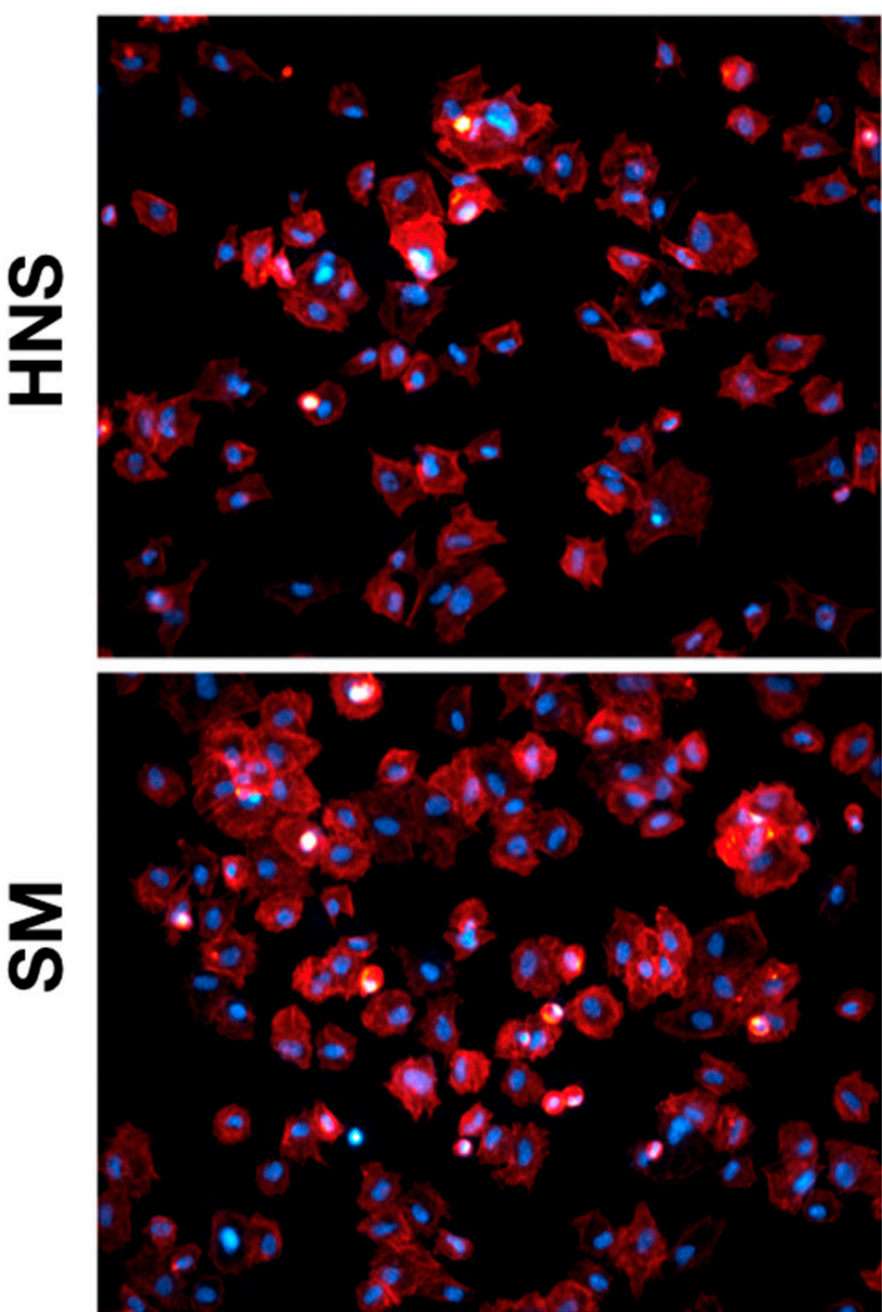

T2
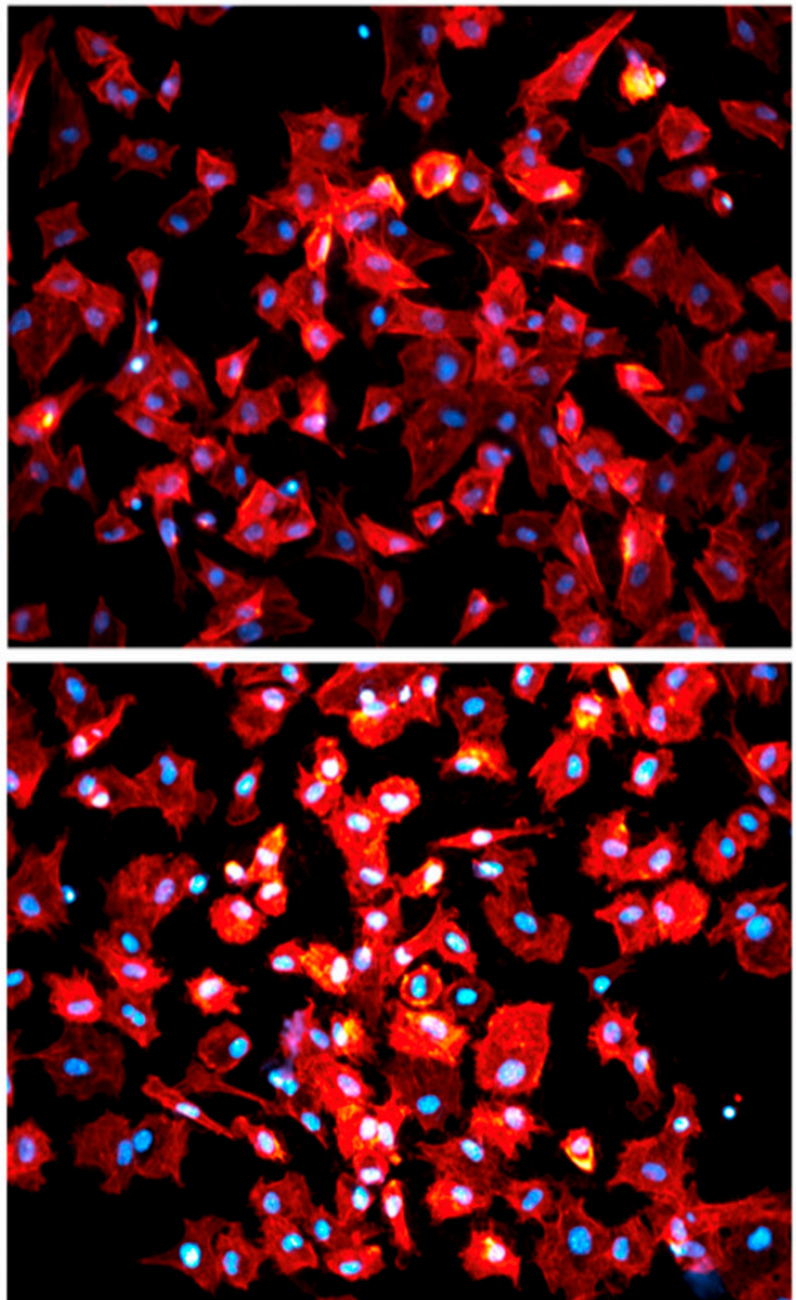

Figure 2. Early cell morphology. Panel depicting the early morphological characterization performed on adherent MC3T3-E1 osteoblasts seed at $2 \mathrm{~h}$ (T1) and $6 \mathrm{~h}$ (T2) on HNS and SM surfaces. The cytoskeleton is labeled red with Rhodamine-Phalloidin. Cell nuclei are stained blue with DAPI.

In order to investigate the morphological differences of the MC3T3-E1 $24 \mathrm{~h}$ after seeding on the different surfaces, different magnifications were considered (100, 200, and $600 \mathrm{X})$. Cells were labeled in order to highlight the cytoskeleton, nucleus, and focal adhesion points through paxillin labeling.

As it is possible to appreciate in Figure 3, cells seeded on the HNS surface appear much more elongated and fusiform than those grown on the SM surface, which instead showed a greater spreading. Furthermore, the cells on the HNS surface have long, intertwining filopodia. Overall, as observed in the quantification of cellular areas, the cells grown on the SM surface have a significantly greater cellular area than those grown on the HNS surface. Observing qualitatively the labeling of paxillin (in red), no important differences in the arrangement of focal adhesions are appreciated, however, it is possible to notice a slight increase in the amount of red staining in the cells grown on the SM surface. 


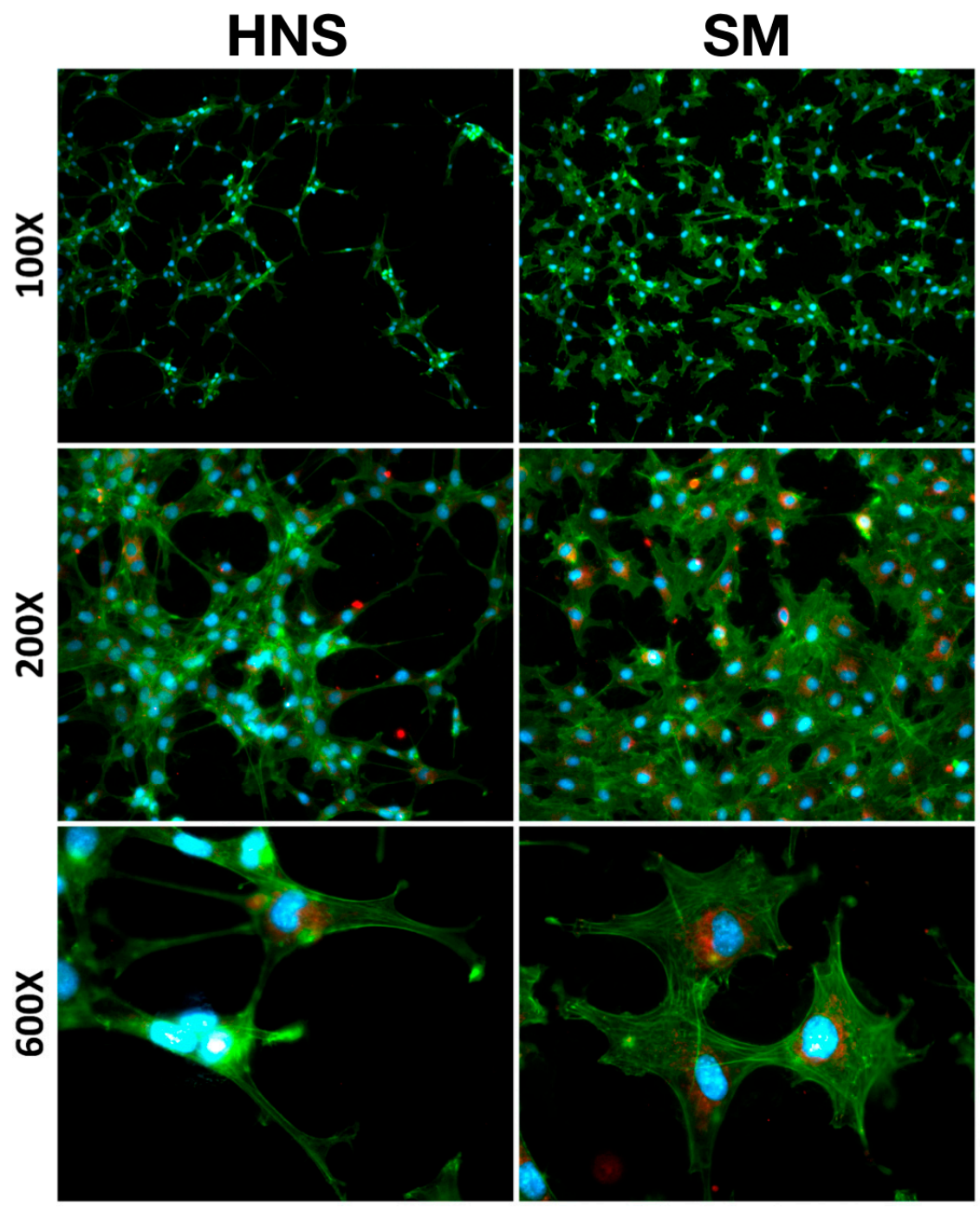

Cell Area

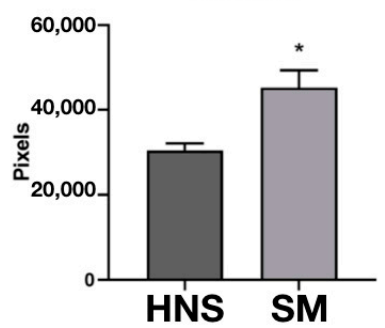

Figure 3. Cell Morphology. MC3T3-E1 seed on HNS and SM sample after $24 \mathrm{~h}$. Staining for Focal Adhesions (Paxillin in red), cytoskeleton (actin, Alexafluor 488-phalloidin in green), neclui (DAPI in blue). Images were acquired at 100, 200, and 600 magnifications. Quantification of cell area performed with ImageJ. Values represent mean \pm SEM. The symbol $\left(^{*}\right)$ indicates the statistical significance vs. HNS surface, considering a $p$-value $<0.05$.

\subsection{Cell Proliferation}

Cell proliferation on HNS and SM surfaces was then evaluated. No significant differences are observed at $24 \mathrm{~h}$, however, starting from $48 \mathrm{~h}$, it is possible to appreciate a significant increase in the proliferation of cells seeded on the SM surfaces compared to those on HNS. This difference is particularly evident considering the data at $120 \mathrm{~h}$ (Figure 4). 


\section{Proliferation}

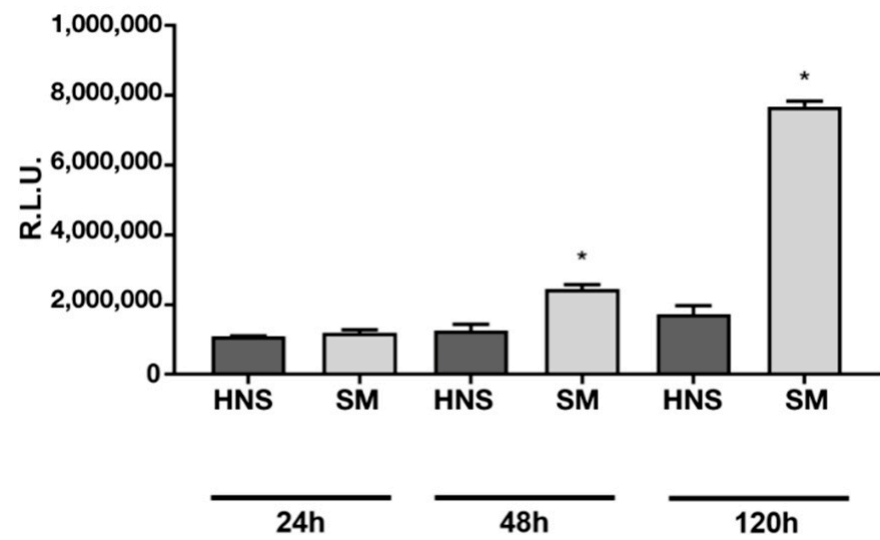

Figure 4. Cell proliferation assay measured using CellTiter-GLO at 24, 48, and $120 \mathrm{~h}$, measuring the luminescence through a microplate reader. Values represent mean \pm SEM. The symbol $(*)$ indicates the statistical significance vs. HNS surface, considering a $p$-value $<0.05$.

\subsection{Osteogenic Activity}

Finally, the ability of HNS and SM surfaces to impact the osteoblastic differentiation of MC3T3-E1 pre-osteoblasts was evaluated. The cells were grown in osteogenic medium for 21 days, and the calcium deposits were then measured by Alizarin Red S staining, and the activity of alkaline phosphatase was evaluated on both the culture medium and the cell lysate.

As it is possible to appreciate in Figure $5 \mathrm{~A}, \mathrm{~B}$, the HNS surface is able to determine an impressive and significant increase in the calcium deposit compared to the SM surfaces.

A

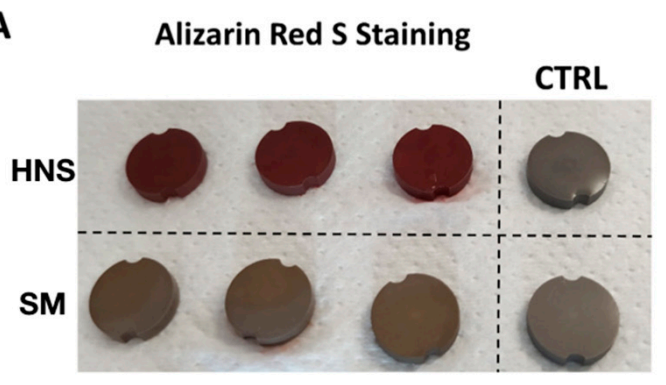

B

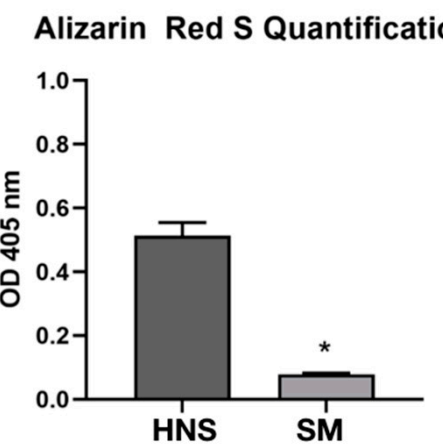

\section{C}

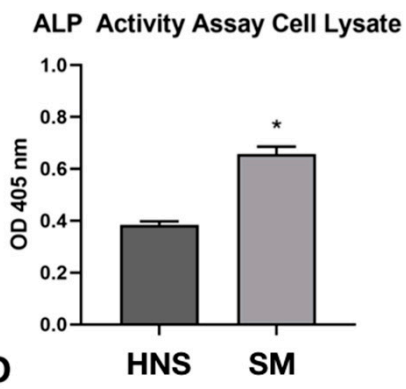

ALP Activity Assay Medium

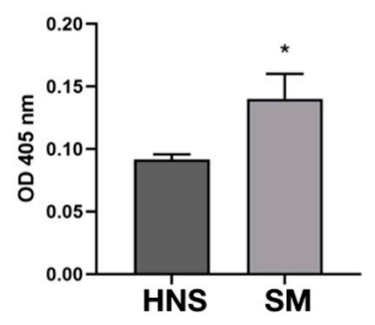

Figure 5. Osteogenic activity of MC3T3-E1 cultured for 21 days in osteogenic medium on HNS or SM surfaces. Representative picture of staining of calcium deposit on titanium samples through Alizarin Red S (A). Quantification of optical density at $405 \mathrm{~nm}$ of solubilized Alizarin Red S staining with $10 \%$ acetic acid (B). Evaluation of ALP activity on cell lysate (C) and culture medium (D) of MC3T3-E1 by using ALP Activity Assay Kit ab83369 (Abcam). Values represent mean \pm SEM. The symbol $\left({ }^{*}\right)$ indicates the statistical significance vs. HNS surface, considering a $p$-value $<0.05$. 
Surprisingly, the cells grown on the SM surfaces show, on the contrary, a significant increase in the activity of alkaline phosphatase both in the cell lysate Figure 5C and in the culture medium Figure 5D.

\section{Discussion}

New technologies and research in the dental implant field have led, in the last decade, to a higher success rate and a better understanding of osteointegration processes [29]. Progress mainly derived from new implant surface and, consequently, the introduction of devices with different roughness, wettability, and chemistry [30]. These variables are strongly related, and understanding their role in the osteointegration process has given implants superior clinical outcomes. The topography of the surfaces has been developed at the micro $(1-10 \mu \mathrm{m})$ and nano level $(1-100 \mathrm{~nm})$. Micro-roughened surfaces are obtained with SLA or anodic oxidation treatments, while nano-roughened surfaces derived from $\mathrm{TiO}_{2}$ nanotube layer, Coating with Hydroxyapatite or Calcium-Phosphorus Compound or Functional Peptides, Photofunctionalization, Laser Ablation, and Flouride Treatment by Cathodic Reduction [31]. HNS surface showed encouraging results in vitro [32]. Several studies suggest that nanostructured topography provides a structure analogous to natural bone enhancing protein absorption and the signaling pathways controlling cells adhesion, proliferation, and differentiation [33,34]. Surface wettability is another crucial aspect of osseointegration [35]. Wettability is quantified by the Contact Angle (CA), and hydrophilic, hydrophobic, superhydrophilic, or superhydrophobic surfaces are recognized. Most in vitro studies highlight those hydrophilic surfaces enhance early osteointegration due to close interaction with biological fluids and better protein adsorption [36,37]. However, some studies suggest that extremely high surface energies can hinder motility and cell functions [38]. Implant chemistry is modified by means of different coating materials, including carbon, bisphosphonates, bioactive glass and ceramics, fluoride, hydroxyapatite and calcium phosphate, Ti-nitride and salts [39]. In this study, a new surface created by adding salts to an SM surface (HNS) was tested. Salt's addition was made in order to improve the wettability and stabilize the hydrophilic surfaces over time, avoiding wet storage [40]. It is quite interesting to note that SM surface determines a slight but significant increase in cell adhesion in a short time compared to HNS surface. It has been observed that large increases in cell adhesion could also correlate with increases in cell spreading at an early time. In this study, we observed a slight difference in the level of spreading, which is greater at T2 than at T1, with cells seeded on HNS surfaces appearing very slightly more elongated and less round than those seeded on SM surfaces indicating faster differentiation on HNS surfaces.

HNS surface has long and intertwining filopodia that could be a response of cells to surface nano-topography that results in a higher stage of differentiation.

This could indicate that in the SM surface there is a greater proliferation and cell adhesion which is not an aspect that implies a faster differentiation.

As mentioned above, cell morphological differences are much more evident $24 \mathrm{~h}$ after seeding. It is possible to observe that cells on the SM surface are rounder, with greater cell spreading and that these cells have a tendency to aggregate more than those on the HNS surface. Although it is necessary to deepen with further studies, this phenomenon could be related to the tendency to proliferate more on this surface. Indeed, the proliferation essay showed statistically significant differences between HNS and SM at $48 \mathrm{~h}$ and $120 \mathrm{~h}$, with SM surface greatly enhancing proliferation. Although the precise mechanism is still unknown and further studies are needed, these results could also be due to the residual impurity and contaminants on HNS surface hindering proliferation despite its ideal topography and hydrophilicity. The difference between HNS and SM can be also attributable to in vitro experimental conditions, and other studies are needed to clarify the role of Bioactivation with salt in the early stages of healing.

Finally, we focused on the effects of bone differentiation on considered surfaces. To this end, we evaluated calcium deposits and alkaline phosphatase activity, two classic 
indicators of bone differentiation. It is very interesting to observe that HNS surface can significantly increase calcium mineralization deposits compared to SM surfaces. However, considering alkaline phosphatase activity, it is surprising to note that it is higher in cells grown on SM surface.

In order to interpret these data, some speculations can be made, which will be clarified in subsequent studies. It is possible that the nature of the HNS surface is more prone to determine the deposition of calcium minerals but also that the cells on this surface are able to deposit calcium in greater quantities. On the other hand, we have shown that cells on the SM surface proliferate more. Treatment with an osteodifferentiating medium is known to induce the reduction of proliferation in favor of osteodifferentiation. Despite this, it is possible that cells on the SM surface could proliferate more than those on the HNS surface (especially in the initial stages of induction), and this could contribute to a greater amount of alkaline phosphatase resulting in an increase in its total activity.

Many studies have evaluated the early biological response of super hydrophilic dental implant surfaces [41-46], showing increased attachment, proliferation and osteogenic potential of osteoblast-like cells. However, there are no similar studies in the literature able to compare sandblasted and acid etched surfaces with bioactive ones activated by salts. The activity of the salt layer, in terms of increasing surface energy, is encouraging and the purity of the grade 23 Titanium surface is also demonstrated by salts total ability to dissolve in contact with fluids. This study is the first investigating the role of salts layer during the first phase of healing and it has been shown that the benefits are associated with the massive deposition of calcium salts. A study of Bagambisa et al. [47] showed that culture experiments have not always been correlated to in vivo results so this potential and interesting biochemical advantage should be validated by future animal studies with the aim of evaluating the rate of bone implant contact in the early stages of healing.

\section{Conclusions}

Notwithstanding all the limitations of this in vitro study, it is possible to state that further investigation is needed to understand chemical interactions and eventual clinical advantages in the osseointegration process due to dry bioactivation of implant surfaces with salt.

Author Contributions: Conceptualization, F.G. and L.C.; methodology, P.B.; software, C.R.; validation, C.R., F.M., G.C. and T.G.; formal analysis, P.B. and G.C.; investigation, F.G. and L.C.; resources, D.A.; data curation, C.R.; writing-original draft preparation, F.M.; writing-review and editing, L.C.; visualization, F.M.; supervision, T.G.; project administration, P.B.; funding acquisition, C.R. All authors have read and agreed to the published version of the manuscript.

Funding: This research received no external funding.

Institutional Review Board Statement: Not applicable.

Informed Consent Statement: Not applicable.

Data Availability Statement: Not applicable.

Conflicts of Interest: The authors declare no conflict of interest.

\section{References}

1. Albrektsson, T.; Brånemark, P.I.; Hansson, H.A.; Lindström, J. Osseointegrated titanium implants. Requirements for ensuring a long-lasting, direct bone-to-implant anchorage in man. Acta Orthop. Scand. 1981, 52, 155-170. [CrossRef] [PubMed]

2. Guéhennec, L.E.; Soueidan, A.; Layrolle, P.; Amouriq, Y. Surface treatments of titanium dental implants for rapid osseointe-gration. Dent Mater. 2007, 23, 844-854. [CrossRef]

3. Ferguson, S.J.; Broggini, N.; Wieland, M.; de Wild, M.; Rupp, F.; Geis-Gerstorfer, J.; Cochran, D.L.; Buser, D. Biomechanical evalua-tion of the interfacial strength of a chemically modified sandblasted and acid-etched titanium surface. J. Biomed. Mater. Res. A 2006, 78, 291-297. [CrossRef] [PubMed]

4. Schwartz, Z.; Boyan, B.D. Underlying mechanisms at the bone-biomaterial interface. J. Cell. Biochem. 1994, 56, 340-347. [CrossRef] [PubMed] 
5. Zinger, O.; Zhao, G.; Schwartz, Z.; Simpson, J.; Wieland, M.; Landolt, D.; Boyan, B. Differential regulation of osteoblasts by sub-strate microstructural features. Biomaterials 2005, 26, 1837-1847. [CrossRef] [PubMed]

6. Romero-Ruiz, M.M.; Gil, F.; Ríos-Santos, J.V.; Lázaro-Calvo, P.; Ríos-Carrasco, B.; Herrero-Climent, M. Influence of a Novel Surface of Bioactive Implants on Osseointegration: AComparative and Histomorfometric Correlation and Implant Stability Study in Minipigs. Int. J. Mol. Sci. 2019, 20, 2307. [CrossRef]

7. Lang, N.P.; Salvi, G.E.; Huynh-Ba, G.; Ivanovski, S.; Donos, N.; Bosshardt, D.D. Early osseointegration to hydrophilic and hy-drophobic implant surfaces in humans. Clin. Oral Implants Res. 2011, 22, 349-356. [CrossRef]

8. Gittens, R.A.; Scheideler, L.; Rupp, F.; Hyzy, S.L.; Geis-Gerstorfer, J.; Schwartz, Z.; Boyan, B.D. A review on the wettability of den-tal implant surfaces II: Biological and clinical aspects. Acta Biomater. 2014, 10, 2907-2918. [CrossRef] [PubMed]

9. Lotz, E.M.; Olivares-Navarrete, R.; Berner, S.; Boyan, B.D.; Schwartz, Z. Osteogenic response of human MSCs and osteoblasts to hydrophilic and hydrophobic nanostructured titanium implant surfaces. J. Biomed. Mater. Res. Part A 2016, 104, 3137-3148. [CrossRef]

10. Buser, D.; Broggini, N.; Wieland, M.; Schenk, R.K.; Denzer, A.J.; Cochran, D.L.; Hoffmann, B.; Lussi, A.; Steinemann, S.G. Enhanced Bone Apposition to a Chemically Modified SLA Titanium Surface. J. Dent. Res. 2004, 83, 529-533. [CrossRef]

11. Hotchkiss, K.M.; Reddy, G.B.; Hyzy, S.L.; Schwartz, Z.; Boyan, B.D.; Olivares-Navarrete, R. Titanium surface characteristics, in-cluding topography and wettability, alter macrophage activation. Acta Biomater. 2016, 31, 425-434. [CrossRef] [PubMed]

12. Shen, J.-W.; Chen, Y.; Yang, G.-L.; Wang, X.-X.; He, F.-M.; Wang, H.-M. Effects of storage medium and UV photofunctionalization on time-related changes of titanium surface characteristics and biocompatibility. J. Biomed. Mater. Res. Part B Appl. Biomater. 2016, 104, 932-940. [CrossRef]

13. Canullo, L.; Penarrocha Oltra, D.; Pesce, P.; Zarauz, C.; Lattanzio, R.; Penarrocha Diago, M.; Iezzi, G. Soft tissue integration of different abutment surfaces: An experimental study with histological analysis. Clin. Oral Implants Res. 2021. Epub ahead of print. [CrossRef] [PubMed]

14. Kilpadi, D.V.; Lemons, J.E. Surface energy characterization of unalloyed titanium implants. J. Biomed. Mater. Res. 1994, 28, 1419-1425. [CrossRef]

15. Rupp, F.; Gittens, R.A.; Scheideler, L.; Marmur, A.; Boyan, B.D.; Schwartz, Z.; Geis-Gerstorfer, J. A review on the wettability of dental implant surfaces I: Theoretical and experimental aspects. Acta Biomater. 2014, 10, 2894-2906. [CrossRef]

16. Rupp, F.; Scheideler, L.; Rehbein, D.; Axmann, D.; Geis-Gerstorfer, J. Roughness induced dynamic changes of wettability of acid etched titanium implant modifications. Biomaterials 2004, 25, 1429-1438. [CrossRef]

17. Zisman, W.A. Relation of the equilibrium contact angle to liquid and solid constitution. In Contact Angle, Wettability, and Adhesion; Fowkes, F.W., Ed.; ACS Publications: Washington, DC, USA, 1964; Chapter 1, pp. 1-51. [CrossRef]

18. Att, W.; Hori, N.; Takeuchi, M.; Ouyang, J.; Yang, Y.; Anpo, M.; Ogawa, T. Time-dependent degradation of ti-tanium osteoconductivity: An implication of biological aging of implant materials. Biomaterials 2009, 30, 5352-5363. [CrossRef] [PubMed]

19. Baier, R.E.; Meyer, A.E. Future directions in surface preparation of dental implants. J. Dent. Educ. 1988, 52, 788-791. [CrossRef]

20. Chambrone, L.; Shibli, J.A.; Mercúrio, C.E.; Cardoso, B.; Preshaw, P.M. Efficacy of standard (SLA) and modi-fied sandblasted and acidetched (SLActive) dental implants in promoting immediate and/or early occlusal loading proto-cols: A systematic review of prospective studies. Clin. Oral Implants Res. 2015, 26, 359-370. [CrossRef] [PubMed]

21. Jennissen, H.P. Stabilizing ultra-hydrophilic surfaces by an exsiccation layer of salts and implications of the hofmeister effect. Materialwiss. Werkstofftech. Mater. Sci. Eng. Technol. 2010, 41, 1035-1039.

22. Canullo, L.; Genova, T.; Tallarico, M.; Gautier, G.; Mussano, F.; Botticelli, D. Plasma of argon affects the earliest biological response of different implant surfaces: An in vitro comparative study. J. Dent. Res. 2016, 95, 566-573. [CrossRef]

23. Choi, S.-H.; Jeong, W.-S.; Cha, J.-Y.; Lee, J.-H.; Lee, K.-J.; Yu, H.-S.; Choi, E.-H.; Kim, K.-M.; Hwang, C.-J. Overcoming the biological aging of titanium using a wet storage method after ultraviolet treatment. Sci. Rep. 2017, 7, 3833. [CrossRef]

24. Morra, M.; Cassinelli, C.; Torre, E.; Iviglia, G. Permanent wettability of a novel, nanoengineered, clinically available, hyalu-ronancoated dental implant. Clin. Exp. Dent. Res. 2018, 4, 196-205. [CrossRef] [PubMed]

25. Lüers, S.; Laub, M.; Jennissen, H.P. Protecting ultra- and hyperhydrophilic implant surfaces in dry state from loss of wettability. Curr. Dir. Biomed. Eng. 2016, 2, 557-560. [CrossRef]

26. Gianfreda, F.; Antonacci, D.; Raffone, C.; Muzzi, M.; Pistilli, V.; Bollero, P. Microscopic Characterization of Bioactivate Implant Surfaces: Increasing Wettability Using Salts and Dry Technology. Materials 2021, 14, 2608. [CrossRef]

27. Canullo, L.; Micarelli, C.; Fazio, L.L.; Iannello, G.; Clementini, M. Microscopical and microbiologic characterization of customized titanium abutments after different cleaning procedures. Clin. Oral Implants Res. 2012, 25, 328-336. [CrossRef] [PubMed]

28. Mussano, F.; Genova, T.; Petrillo, S.; Roato, I.; Ferracini, R.; Munaron, L. Osteogenic Differentiation Modulates the Cytokine, Chemokine, and Growth Factor Profile of ASCs and SHED. Int. J. Mol. Sci. 2018, 19, 1454. [CrossRef]

29. Rupp, F.; Liang, L.; Geis-Gerstorfer, J.; Scheideler, L.; Hüttig, F. Surface characteristics of dental implants: A review. Dent. Mater. 2018, 34, 40-57. [CrossRef]

30. Gittens, R.A.; Olivares-Navarrete, R.; Cheng, A.; Anderson, D.; McLachlan, T.; Stephan, I.; Geis-Gerstorfer, J.; Sandhage, K.H.; Fedorov, A.G.; Rupp, F.; et al. The roles of titanium surface micro/nanotopography and wettability on the differential response of human osteoblast lineage cells. Acta Biomater. 2013, 9, 6268-6277. [CrossRef] [PubMed]

31. Yeo, I.-S.L. Modifications of Dental Implant Surfaces at the Micro- and Nano-Level for Enhanced Osseointegration. Materials 2019, 13, 89. [CrossRef] 
32. Rupp, F.; Scheideler, L.; Eichler, M.; Geis-Gerstorfer, J. Wetting behavior of dentalimplants. Int. J. Oral Maxillofac. Implants 2011, $26,1256-1266$

33. Engel, E.; Michiardi, A.; Navarro, M.; Lacroix, D.; Planell, J.A. Nanotechnology in regenerative medicine: The materials side. Trends Biotechnol. 2008, 26, 39-47. [CrossRef]

34. Khang, D.; Choi, J.; Im, Y.M.; Kim, Y.J.; Jang, J.H.; Kang, S.S.; Nam, T.H.; Song, J.; Park, J.W. Role of subnano-, nano- and submicron-surface features on osteoblast differentiation of bone marrow mesenchymal stem cells. Biomaterials 2012, 33, 5997-6007. [CrossRef] [PubMed]

35. Wennerberg, A.; Albrektsson, T. On implant surfaces: A review of current knowledge and opinions. Int. J. Oral Maxillofac. Implants 2010, 25, 63-74.

36. Eriksson, C.; Nygren, H.; Ohlson, K. Implantation of hydrophilic and hydrophobic titanium discs in rat tibia: Cellular reac-tions on the surfaces during the first 3 weeks in bone. Biomaterials 2004, 25, 4759-4766. [CrossRef] [PubMed]

37. Spijker, H.T.; Graaff, R.; Boonstra, P.W.; Busscher, H.J.; van Oeveren, W. On the influence of flow conditions and wettability on blood material interactions. Biomaterials 2003, 24, 4717-4727. [CrossRef]

38. Qiu, Q.; Sayer, M.; Kawaja, M.; Shen, X.; Davies, J.E. Attachment, morphology, and protein expression of rat marrow stromal cells cultured on charged substrate surfaces. J. Biomed. Mater. Res. 1998, 42, 117-127. [CrossRef]

39. Xuereb, M.; Camilleri, J.; Attard, N.J. Systematic review of current dental implant coating materials and novel coating tech-niques. Int. J. Prosthodont. 2015, 28, 51-59. [CrossRef]

40. Jennissen, H. Stabilizing ultra-hydrophilic surfaces by an exsiccation layer of salts and implications of the Hofmeistereffect. Stabilisierung ultra-hydrophiler Oberflächen durch eine Exsikkationsschicht aus Salzen und Bedeutung des Hof-meister-Effektes. Materialwissenschaft Und Werkstofftechnik 2010, 41, 1035-1039. [CrossRef]

41. Salido, M.; Vilches, J.I.; Gutierrez, J.L.; Vilches, J. Actin cytoskeletal organization in human osteoblasts grown on different dental titanium implant surfaces. Histol. Histopathol. 2007, 22, 1355-1364.

42. Yamamura, K.; Miura, T.; Kou, I.; Muramatsu, T.; Furusawa, M.; Yoshinari, M. Influence of various superhydrophilic treatments of titanium on the initial attachment, proliferation, and differentiation of osteoblast-like cells. Dent. Mater. J. 2015, 34, 120-127. [CrossRef] [PubMed]

43. Eguro, T.; Murata, I.; Ohashi, I.; Maekawa, S.; Yoshinari, M. Influence of surface chemical modification on hydrophilicity of ti-tanium. J. Jpn. Soc. Oral Implant 2011, 24, 215-224.

44. Qu, Z.; Rausch-Fan, X.; Wieland, M.; Matejka, M.; Schedle, A. The initial attachment and subsequent behavior regulation of osteoblasts by dental implant surface modification. J. Biomed. Mater. Res. Part A 2007, 82, 658-668. [CrossRef] [PubMed]

45. Zhao, G.; Schwartz, Z.; Wieland, M.; Rupp, F.; Geis-Gerstorfer, J.; Cochran, D.L.; Boyan, B.D. High surface energy enhances cell response to titanium substrate microstructure. J. Biomed. Mater. Res. Part A 2005, 74, 49-58. [CrossRef]

46. Klein, M.O.; Bijelic, A.; Toyoshima, T. Long-term response of osteogenic cells on micron and submicron- scale-structured hydrophilic titanium surfaces: Sequence of cell proliferation and cell differentiation. Clin. Oral Implants Res. 2010, 21, 642-649. [CrossRef]

47. Bagambisa, F.B.; Joos, U.; Schilli, W. The interaction of osteogenic cells with hydroxyapatite implant materials in vivo and in vitro. Int. J. Oral Maxillofac. Implants 1990, 5, 217-226. 